\title{
Sampling Plan for Diaphania spp. (Lepidoptera: Pyralidae) and for Hymenopteran Parasitoids on Cucumber
}

Author(s): Leandro Bacci, Marcelo C. Picanço, Marcelo F. Moura, Terezinha M. C. Della Lucia, and Altair A. Semeão

Source: Journal of Economic Entomology, 99(6):2177-2184.

Published By: Entomological Society of America

https://doi.org/10.1603/0022-0493-99.6.2177

URL: http://www.bioone.org/doi/full/10.1603/0022-0493-99.6.2177

BioOne (www.bioone.org) is a nonprofit, online aggregation of core research in the biological, ecological, and environmental sciences. BioOne provides a sustainable online platform for over 170 journals and books published by nonprofit societies, associations, museums, institutions, and presses.

Your use of this PDF, the BioOne Web site, and all posted and associated content indicates your acceptance of BioOne's Terms of Use, available at www.bioone.org/page/ terms of use.

Usage of BioOne content is strictly limited to personal, educational, and non-commercial use. Commercial inquiries or rights and permissions requests should be directed to the individual publisher as copyright holder. 


\title{
Sampling Plan for Diaphania spp. (Lepidoptera: Pyralidae) and for Hymenopteran Parasitoids on Cucumber
}

\author{
LEANDRO BACCI, ${ }^{1}$ MARCELO C. PICANÇO, MARCELO F. MOURA, \\ TEREZINHA M. C. DELLA LUCIA, AND ALTAIR A. SEMEÃO
}

Departamento de Biologia Animal, Universidade Federal de Viçosa, 36571-000 Viçosa, Minas Gerais State, Brazil

J. Econ. Entomol. 99(6): 2177-2184 (2006)

\begin{abstract}
The objective of this work was to determine the best technique, sampling unit, and the number of samples to compose a conventional sampling plan for the cucurbit borers, Diaphania spp. (Lepidoptera: Pyralidae), and for hymenopteran parasitoids on cucumber. This research was carried out in 10 commercial cucumber crops fields from July to December 2000 in Tocantins, Minas Gerais State, Brazil ( $21^{\circ} 11^{\prime} 15^{\prime \prime} \mathrm{S} ; 42^{\circ} 03^{\prime} 45^{\prime \prime} \mathrm{W}$; altitude $363 \mathrm{~m}$ ). The sampling methods studied were beating on a tray, direct counting of insects on the lower leaf surface, and whole leaf collection. Three sampling units also were studied: leaves from a branch located in the apical, median, or basal third of the canopy. The best sampling systems, which included the best technique and sampling unit, were determined based on the relative variance and the economic precision of the sampling. Once the best sampling systems were established, the numbers of samples to compose the conventional sampling plans were determined. The more suitable sampling system for the larvae of Diaphania spp. in cucumber plants was beating a leaf of the median third of the canopy on a plastic tray. One leaf must be sampled for every 50 plants in a crop. The more suitable sampling system for hymenopteran parasitoids in cucumber plants was to directly count the adults on one leaf of the median third of the canopy. One leaf must be sampled for every 74 plants in a crop.
\end{abstract}

KEY WORDS Cucumis sativus, cucurbit borers, natural enemy, decision making

Cucurbit borers, Diaphania spp. (Lepidoptera: Pyralidae), are considered important pests in the southwestern United States, in Central and South America, and in the Caribbean Islands (Smith et al. 1994; Gonring et al. 2003a,b). In cucumber crops, Diaphania spp. are considered as key pests and may cause up to $100 \%$ yield losses of this vegetable (Picanço et al. 2000).

Diaphania species attack leaves as well as fruits at different intensities. Diaphania hyalinata (L.) prefers leaves, whereas Diaphania nitidalis (Stoll) favors leaves during its three first instars but fruit as older instars (Sorensen and Baker 1983). The attack on leaves decreases productivity because of a reduction of the photosynthetic area of the plant. In addition, the attack on fruit makes it inappropriate for market (Sorensen and Baker 1983).

Hymenopteran parasitoids are important agents of natural biological control of cucurbit borers, parasitizing their eggs, larvae, and pupae. D. nitidalis eggs are parasitized by Trichogramma pretiosum Riley (Hymenoptera: Trichogrammatidae) and the larvae by Apanteles sp., Meteorus sp., and Hypomicrogaster sp. (Hymenoptera: Braconidae) (Gonring et al. 2003b). D. hyalinata also is parasitized by the pupal parasitoid Polycyrtus sp. (Hymenoptera: Ichneumonidae) (Gon-

\footnotetext{
${ }^{1}$ Corresponding author, e-mail: bacci@insecta.ufv.br.
}

ring et al. 2003a), in addition to the other species. Although natural biological control of these pests is important, their control has been carried out mainly through successive insecticide applications.

Besides the economic damage, excessive use of insecticides also may contaminate water, air, and soil and interfere with the atmosphere and human health. A way of averting this situation is through the adoption of integrated pest management (IPM), in which a phytophagous insect is only considered a pest when it causes economical damage. In this system, the densities of the pest and its natural enemies are monitored and then compared with decision-making indices for pest control decisions (Pedigo 1988, Dent 2000, Picanço et al. 2000).

The sampling of pests and natural enemies can be carried out following a sequential or conventional plan (Sterling et al. 1983). The conventional sampling plan has a fixed number of samples, uses fixed proceedings of sampling, and requires more time than the sequential plan. The conventional plan represents the initial point of generation of IPM programs for determining essential parameters to decision making, such as the best sampling unit and the sampling method that will be used for determining the economical damage level. In addition, conventional plans are used as patterns for 
validation of sequential plans (Pedigo and Zeiss 1996, Gusmão et al. 2005) .

The sampling technique that best estimates the insect density should consider precision, cost, and statistical distribution of data to make possible a control decision making that is efficient and low cost (Pedigo 1988). Among the sampling techniques used to determine the densities of insects in vegetable leaves are beating leaf on white plastic tray (Pedigo 1988, Gusmão et al. 2005), direct counting of insects (Gusmão et al. 2005), and whole leaf collection (Moura et al. 2003). However, the efficiency of these techniques for sampling of Diaphania spp. and natural enemies in cucumber crops is not known.

In a sampling plan for Diaphania spp., the pest should be evaluated before it starts boring the fruit, because cucumber plants have low recovery capacity from this injury. Monitoring for adults of Diaphania spp. by light and pheromone traps was not found to be efficient (Valles et al. 1991). Evaluation of larvae on leaves is one of the ways of generating a plan with these characteristics. The leaves also can be used for sampling hymenopteran parasitoids (Miranda et al. 1998). Thus, the objective of this work was to determine the best technique, sampling unit, and the number of samples to constitute a conventional sampling plan for cucumber borers, Diaphania spp., and their hymenopteran parasitoids in cucumber.

\section{Materials and Methods}

This work was conducted from July to December 2000 in Tocantins, Minas Gerais State, Brazil $\left(21^{\circ} 11^{\prime} 15^{\prime \prime} \mathrm{S}\right.$; $42^{\circ} 03^{\prime} 45^{\prime \prime} \mathrm{W}$; altitude $\left.363 \mathrm{~m}\right)$, in 10 1.0-ha commercial cucumber crops. The plants were conducted with a stem and spacing of 1.0 by $0.5 \mathrm{~m}$, under local procedures of cultivation, irrigation, fertilization, and weed control. Pests and diseases were not controlled. The densities of Diaphania spp. larvae and of adults hymenopteran parasitoids were evaluated.

The experimental design was in randomized blocks with 10 replications (plots or plantations) in a factorial scheme 3 by 3 (techniques $\times$ sampling unit). In each plot, we collected 1,650 samples from 200 plants (nine samples per plant in 150 plants and six samples per plant in 50 plants). On each sample date, 100 plants were evaluated in one plot. A grid pattern was used to collect samples, and the first plant of the southeastern quadrant of the field was evaluated. There was a similar distance between sampled plants; $5 \mathrm{~m}$ between plants in a row and $5 \mathrm{~m}$ between plant rows. Samples were collected from the entire cucumber plantation to avoid bias in the choice of the sampling place.

Technique and Sampling Unit. Three sampling techniques were used: beating the leaf on white plastic tray (BLPT) $(35 \mathrm{~cm}$ in length by $30 \mathrm{~cm}$ in width by $5 \mathrm{~cm}$ in depth), direct counting of insects (DC) on the abaxial leaf surface, and whole leaf collection (WLC). The sampling units consisted of taking a leaf from either the apical, median, or basal third of the canopy (Moura et al. 2003). Because Diaphania spp. larvae as well as hymenopteran parasitoids occur initially on leaves, leaves were selected for sampling (Miranda et al. 1998).

Beating leaves on a tray consisted of placing a tray under a particular leaf and shaking it rapidly, causing the insects present on the leaf to fall to the tray where they were counted. In the technique of direct counting, the leaf was turned carefully so as not to disturb the insects, and insects found on the abaxial surface of the leaf were counted. In the technique of whole leaf collection, the leaf was quickly enclosed by the plastic bag, cut, and the bag was sealed. The bags with the leaves were taken to the laboratory where the live insects were counted. Each sampling method used different plants. Disturbance to surrounding plants also was minimized (Moura et al. 2003).

The time spent for taking each sample and moving from sample to sample was recorded and used to calculate the cost. Average and standard deviation of densities were calculated for each sampling method, and these data were used to calculate the relative variance according to the formula of Pedigo et al. (1982):

$$
R V=\frac{[100 \times S(\bar{X})]}{\bar{X}}
$$

where $R V$ is relative variance $(\%), S(\bar{X})=$ standard deviation, and $(\bar{X})=$ average.

Relative variance measures the variability of sampling data. The best methods are those with low values for this characteristic. Data of sampling costs and relative variance $(R V)$ were used to calculate the economic precision $(E P)$ of sampling methods by using the expression of Kogan and Herzog (1980):

$$
E P=\frac{100}{[R V \times S c]}
$$

where $S c$ is sampling cost (US\$ per sample).

The $S c$ was calculated through equation

$$
S c_{i}=F c_{i}+\left[M c \times t_{i}\right]
$$

where $S c_{i}$ is the sampling cost for the $i$ sampling system, $F c$ is the fixed cost of materials for the $i$ sampling system, $M c$ is the man power cost per second, and $t_{i}$ is the time spent in seconds for the evaluation of a sample in the $i$ sampling system added to the average of the time spent in seconds to move from sample to sample (40.97 s). For the WLC technique, the time spent in seconds for the evaluation of a sample in the laboratory was added. Each material had its unit cost calculated, considering the use of durable materials (surveyor's table, tray, pencil, and eraser) for one planting period (16 wk) in eight plots. The $M c$ was calculated, considering wages paid per hour to one pair of samplers in Brazil (US\$6.82). (This amount is equivalent to 5 and 2 times the salary in Brazil [US\$155.97] paid for an appraiser and a recorder, respectively.) One dollar is equivalent to 2.244 Reais.

The best sampling methods have economic precision with high values. $E P$ was not calculated for the sampling systems with $R V$ higher than $25 \%$, which 
would lead to a low precision of estimates according to Southwood (1978). Values of relative variance, time, cost, and economic precision were subjected to the Lilliefors' normality test $(P=0.01)$ (PROC TESTE-LF; SAEG Software 2001) and analysis of variance (ANOVA) (PROC ANOVAG, SAEG Software 2001), whereas means of sampling methods were compared by the Scott-Knott test $(P<0.05)$ (PROC TESTE-MD, SAEG Software 2001).

Determination of Number of Samples of the Conventional Sampling Plan. Once the best sampling systems were established, the numbers of samples to compose the conventional sampling plans were determined. Initially the $\mathrm{b}$ coefficient of the Taylor power law was calculated. This coefficient indicates the theoretical frequency distribution to which the data will possibly fit. If $\mathrm{b}>1$, it indicates that the data tend to fit a negative binomial frequency distribution; $\mathrm{b}=1$ indicates that the data fit a Poisson distribution, and $b<1$ indicates the data fit a positive binomial distribution (Navas et al. 1994, Doane et al. 2000).

The Taylor power law was obtained by calculating the linear regression between the data of average and variance transformed into natural logarithms, through equation:

$$
\operatorname{Ln} S^{2}=\operatorname{Ln} a+b \operatorname{Ln} m
$$

where $S^{2}$ is data variance; a is Taylor coefficient, or sampling factor; $b$ is coefficient $\mathrm{b}$ of Taylor, or index of aggregation; $m$ is average of the population; and the value of $a$ is the antilogarithm of the intercept and $b$ is the inclination of the straight line.

The estimated results from the theoretical frequency distribution models indicated by Taylor power law were tested against the observed frequencies by using a chi-square goodness-of-fit test (Ludwig and Reynolds 1988). Such procedure was carried out using the ENSTAT software (Pedigo and Zeiss 1996).

Once the adjustment of the sampling data to a theoretical distribution of frequency for Diaphania spp. and hymenopteran parasitoids (negative binomial distribution for both) was obtained, a method to determine the necessary number of samples in the estimate of the populations of these insects was selected, in accordance to the equation of Young and Young (1998):

$$
N A=\frac{1}{C^{2}}\left(\frac{1}{\mu}+\frac{1}{k}\right)
$$

where NA is the number of samples, $C$ is level of precision, $\mu$ is population average, and $k$ is parameter of the negative binomial distribution.

For the selection of the level of precision to be used in the sampling plan, the $k_{\text {partials }}\left(k_{p}\right)$ of each plantation were calculated following the equation

$$
\hat{k}=\frac{\bar{x}^{2}}{S^{2}-\bar{x}}
$$

where $\hat{k}$ is parameter of negative binomial distribution, $S^{2}$ is variance of sampling data, and $\bar{x}=$ sample average.

The $k_{\text {partials }}$ data of each plantation were used to calculate the numbers of samples, which were submitted to the analysis of regression as a function of the precision levels of $5,10,15,20$, and $25 \%$ at $P<$ 0.05 , selecting the level of precision where the number of samples presented less variation (Gusmão et al. 2005).

The parameter of common aggregation $k_{\text {common }}$ $\left(k_{c}\right)$ of the data of the plantation that adjusted to the pattern of negative binomial distribution was determined according to the method of Bliss and Owen (1958).

The ease of use was adopted as the criterion for the selection of the number of samples to be used in the sampling plan. The goal was to use a minimum number of samples without compromising the use of the necessary labor to other important practical activities, such as fertilization, irrigation, control of diseases and weeds, staking, and harvesting (Pedigo 1988).

A sampling plan can be considered practicable if the time spent by a pair of samplers (an appraiser and a recorder) in the collection of samples in a plantation is not greater than to $1 \mathrm{~h}$. Thus, considering that it would take one more hour for visiting different plantations and for processing of the data, it would be possible for this pair to sample up to four plantations per day (Gusmão et al. 2005).

\section{Results}

Technique and Sampling Unit. Significant differences $(P<0.05)$ were detected among the sampling systems composed by the sampling technique and the canopy position in the sampled densities of larvae of Diaphania spp. $(F=4.54, \mathrm{df}=72, P=0.00017)$ and adult hymenopteran parasitoids $(F=7.78, \mathrm{df}=72, P<$ 0.00001 ). The greater densities of Diaphania spp. were detected by BLPT of the median and basal thirds of the canopy and by WLC of the apical, median, and basal thirds. However, greater densities of hymenopteran parasitoids were detected by DC of insects in the median third of the canopy (Table 1).

Significant differences $(P<0.05)$ were found in the $R V$ of the samplings of Diaphania spp. $(F=10.12, \mathrm{df}=$ $71, P<0.00001)$ and of hymenopteran parasitoids $(F=$ $5.40, \mathrm{df}=69, P=0.00004)$ as functions of the sampling systems. The sampling systems with relative variances $<25 \%$ (Southwood 1978) for Diaphania spp. were as follows: BLPT of the median $(R V=18.65)$ and basal thirds $(R V=19.69)$ of the canopy and the WLC of the apical $(R V=24.85)$, median $(R V=21.91)$, and basal $(R V=22.62)$ thirds of the canopy. During the sampling hymenopteran parasitoids, the lesser relative variances were found in the DC of the apical $(R V=$ $23.30)$, median $(R V=20.10)$, and basal thirds $(R V=$ 20.22) of the canopy (Table 2 ).

Significant effect $(P<0.05)$ of the sampling system was verified on the time $(F=352.27, \mathrm{df}=529, P<$ $0.00001)$ and the cost $(F=535.98, \mathrm{df}=529, P<$ 
Table 1. Densities of Diaphania spp. and their hymenopteran parasitoids (mean \pm SD) as a function of the sampling technique and of the leaf location in the canopy in 10 cucumber crops (Tocantins, Minas Gerais, Brazil)

\begin{tabular}{|c|c|c|c|c|}
\hline \multirow{2}{*}{ Technique } & \multirow{2}{*}{$\begin{array}{c}\text { Third of the } \\
\text { canopy }\end{array}$} & \multirow{2}{*}{$\begin{array}{c}\text { No. } \\
\text { samples }\end{array}$} & \multicolumn{2}{|c|}{ Insects/sample ${ }^{a}$} \\
\hline & & & Diaphania spp. & Parasitoids \\
\hline Beating tray method & Apical & 2,000 & $0.484 \pm 0.019 \mathrm{~B}$ & $0.109 \pm 0.003 \mathrm{C}$ \\
\hline Beating tray method & Median & 2,000 & $0.722 \pm 0.025 \mathrm{~A}$ & $0.099 \pm 0.003 \mathrm{C}$ \\
\hline Beating tray method & Basal & 2,000 & $0.776 \pm 0.027 \mathrm{~A}$ & $0.070 \pm 0.001 \mathrm{C}$ \\
\hline Direct counting & Apical & 2,000 & $0.163 \pm 0.006 \mathrm{~B}$ & $0.411 \pm 0.010 \mathrm{~B}$ \\
\hline Direct counting & Median & 2,000 & $0.151 \pm 0.005 \mathrm{~B}$ & $0.567 \pm 0.011 \mathrm{~A}$ \\
\hline Direct counting & Basal & 2,000 & $0.194 \pm 0.006 \mathrm{~B}$ & $0.345 \pm 0.005 \mathrm{~B}$ \\
\hline Plastic bag & Apical & 1,500 & $0.730 \pm 0.031 \mathrm{~A}$ & $0.178 \pm 0.006 \mathrm{C}$ \\
\hline Plastic bag & Median & 1,500 & $0.855 \pm 0.029 \mathrm{~A}$ & $0.133 \pm 0.003 \mathrm{C}$ \\
\hline Plastic bag & Basal & 1,500 & $0.925 \pm 0.032 \mathrm{~A}$ & $0.166 \pm 0.008 \mathrm{C}$ \\
\hline
\end{tabular}

${ }^{a}$ Values in each column followed by the same letter do not differ among themselves by the Scott-Knott test $(P<0.05)$.

0.00001) of sampling of Diaphania spp. and hymenopteran parasitoids. The sampling systems with reduced time and cost per sample were BLPT and DC on leaf of apical (51.94 s, US $\$ 0.0991 ; 51.79 \mathrm{~s}$, US $\$ 0.0986)$ and median thirds ( $51.77 \mathrm{~s}$, US $\$ 0.0987 ; 52.94 \mathrm{~s}$, US $\$ 0.1008$ ) of the canopy (Table 2).

Significant differences $(P<0.05)$ were detected in the sampling systems in the economic precisions $(E P)$ of the samplings of Diaphania spp. $(F=28.61, \mathrm{df}=27$, $P<0.00001)$ and hymenopteran parasitoids $(F=4.57$, $\mathrm{df}=18, P=0.02480)$. The sampling systems with greater economic precisions for sampling of Diaphania spp. were BLPT of the median $(E P=74.60)$ and basal ( $E P=75.33)$ thirds of the canopy. However, in the sampling of hymenopteran parasitoids, the greater economic precisions were found in the DC of the apical $(E P=70.22)$ and median $(E P=72.25)$ thirds of the canopy (Table 2).

Therefore, based on the economic precision, the best sampling systems for Diaphania spp. were BLPT of the median or basal third of the canopy. The most accurate sampling systems for the hymenopteran parasitoids were the DC of the apical or median third of the canopy.

Determination of Number of Samples to Compose the Conventional Sampling Plan. The coefficient b of the Taylor power law for sampling of Diaphania spp. by BLPT of the median $(b=1.21)$ and basal $(b=1.15)$ thirds and for sampling hymenopteran parasitoids by the DC of the apical $(b=1.10)$ and median $(b=1.16)$ third were not $<1$ (Fig. 1). This finding indicates that the field data tend to adjust to the Poisson distribution $($ if $\mathrm{b}=1$ ) or negative binomial distribution (if $\mathrm{b}>1$ ) (Taylor 1961).

Densities of Diaphania spp. sampled by BLPT of the median third fit the negative binomial distribution in five of the six plantations tested and fit the Poisson distribution in only two plantations. The densities of Diaphania spp. sampled by BLPT of basal third also fit the negative binomial distribution in the six tested plantations, but these data fit the Poisson distribution in only one plantation (Table 3 ).

Densities of hymenopteran parasitoids sampled by their DC of the apical and median thirds fit the negative binomial distribution in the six tested plantations and adjusted to the Poisson distribution in only two plantations (Table 4).

As the sample distribution of Diaphania spp. and their hymenopteran parasitoids fitted the negative binomial distribution, the number of samples required for the sampling plan was estimated based on this distribution model.

The number of samples needed to estimate Diaphania spp. by BLPT of the median and basal thirds and their hymenopteran parasitoids by DC of the apical and median thirds stabilized at $20 \%$ of precision (Fig. 2), which indicated that the practicable number of samples was given by this precision level.

Table 2. Relative variance, time, cost, and economic precision of samplings of Diaphania spp. (Lepidoptera: Pyralidae) and their hymenopteran parasitoids as function of the sampling technique and the leaf location in the canopy in 10 cucumber crops (Tocantins, Minas Gerais, Brazil)

\begin{tabular}{|c|c|c|c|c|c|c|c|}
\hline \multirow{2}{*}{ Technique } & \multirow{2}{*}{$\begin{array}{l}\text { Part of the } \\
\text { canopy }\end{array}$} & \multicolumn{2}{|c|}{ Relative variance $(\%)^{a}$} & \multirow{2}{*}{$\begin{array}{c}\text { Time } \\
(\mathrm{s} / \mathrm{sample})^{a}\end{array}$} & \multirow{2}{*}{$\begin{array}{c}\text { Cost } \\
(\mathrm{US} \$ / \text { sample })^{a}\end{array}$} & \multicolumn{2}{|c|}{ Economic precision $^{a}$} \\
\hline & & Diaphania spp. & Parasitoids & & & Diaphania spp. & Parasitoids \\
\hline Beating tray method & Apical & $27.54 \mathrm{C}$ & $40.37 \mathrm{~A}$ & $51.94 \mathrm{D}$ & $0.0991 \mathrm{D}$ & $-^{b}$ & - \\
\hline Beating tray method & Median & $18.65 \mathrm{D}$ & $37.77 \mathrm{~A}$ & $51.77 \mathrm{D}$ & $0.0987 \mathrm{D}$ & $74.60 \mathrm{~A}$ & - \\
\hline Beating tray method & Basal & 19.69D & $47.16 \mathrm{~A}$ & $54.11 \mathrm{C}$ & $0.1032 \mathrm{C}$ & $75.33 \mathrm{~A}$ & - \\
\hline Direct counting & Apical & $43.89 \mathrm{~A}$ & $23.30 \mathrm{~B}$ & $51.79 \mathrm{D}$ & $0.0986 \mathrm{D}$ & - & $70.22 \mathrm{~A}$ \\
\hline Direct counting & Median & $34.25 \mathrm{~B}$ & $20.10 \mathrm{~B}$ & $52.94 \mathrm{D}$ & $0.1008 \mathrm{D}$ & - & $72.25 \mathrm{~A}$ \\
\hline Direct counting & Basal & $30.01 \mathrm{C}$ & $20.22 \mathrm{~B}$ & $54.62 \mathrm{C}$ & $0.1039 \mathrm{C}$ & - & $58.43 \mathrm{~B}$ \\
\hline Plastic bag & Apical & $24.85 \mathrm{C}$ & $39.54 \mathrm{~A}$ & $78.85 \mathrm{~B}$ & $0.1631 \mathrm{~B}$ & - & - \\
\hline Plastic bag & Median & $21.91 \mathrm{D}$ & $44.27 \mathrm{~A}$ & $83.18 \mathrm{~A}$ & $0.1714 \mathrm{~A}$ & 41.14B & - \\
\hline Plastic bag & Basal & $22.62 \mathrm{D}$ & $49.36 \mathrm{~A}$ & $84.64 \mathrm{~A}$ & $0.1741 \mathrm{~A}$ & $40.01 \mathrm{~B}$ & - \\
\hline
\end{tabular}

${ }^{a}$ Values in each column followed by the same letter do not differ between themselves by the Scott-Knott test $(P<0.05)$.

${ }^{b}$ These values were not determined because their relative variance was higher than $25 \%$. 

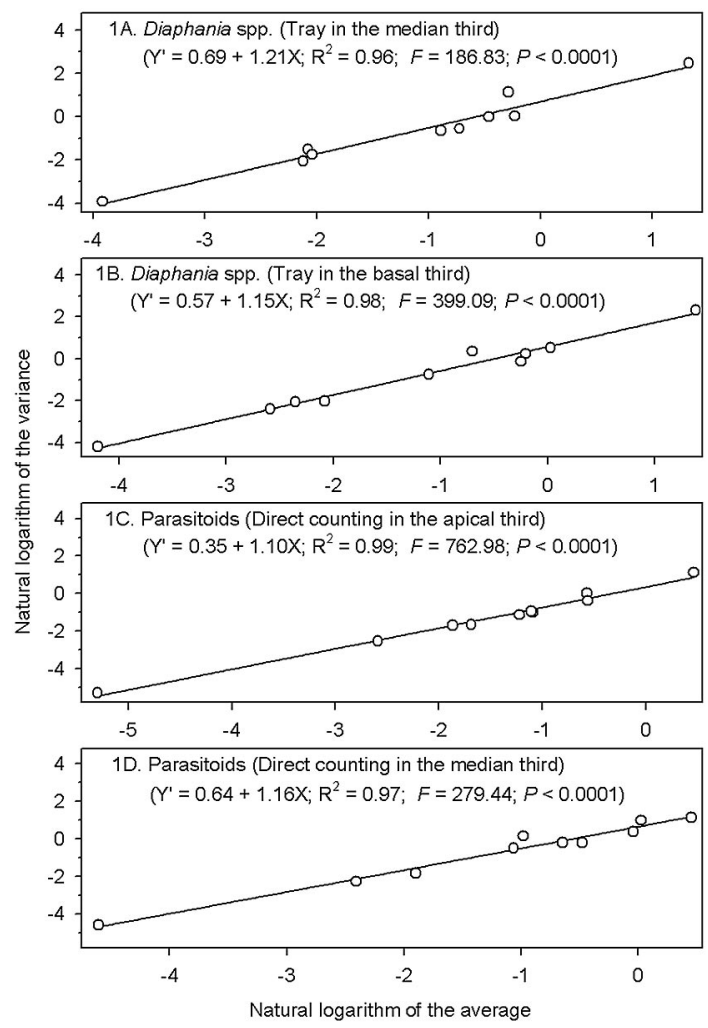

Fig. 1. Natural logarithm of the variance $\left(\mathrm{Ln} \mathrm{S}^{2}\right)$ as function of natural logarithm of the average numbers $(\mathrm{Ln} \mathrm{X})$ of larvae of Diaphania spp. by beating leaf of cucumber of the median (1A) and basal (1B) third of the canopy and adult hymenopteran parasitoids by direct counting on leaf of the apical (1C) and median (1D) third of the canopy on leaves of cucumber plants. Tocantins, Minas Gerais, Brazil.

The two most accurate systems for the sampling of Diaphania spp. (BLPT of the median and basal thirds) had common aggregation parameters $\left(k_{\text {common }}\right)$ of 1.5969 and 1.9670 , respectively $(P<0.05)$. The same occurred with hymenopteran parasitoids by DC of the apical $\left(k_{\text {common }}=1.5890\right)$ and median $\left(k_{\text {common }}=\right.$ 0.8335 ) thirds (Table 5).

The numbers of necessary samples for sampling Diaphania spp. by BLPT of the median and basal thirds of the canopy were of 50 and 44 samples per plantation; time spent was 43.14 and 39.41 min per sampling, with a cost of US\$ 4.94 and 4.51 per sampling, respectively. The necessary number of samples for sampling of adults hymenopteran parasitoids by DC of the apical and median thirds of the canopy were 77 and 74 samples per plantation, with times of 66.46 and 65.29 min per sampling and a cost of US $\$ 17.03$ and 16.73 per sampling, respectively (Table 5 ).

\section{Discussion}

Technique and Sampling Unit. The observation of greater densities of Diaphania spp. by BLPT of the
Table 3. Chi-square test $\left(\chi^{2}\right)$ between observed and expected frequencies by Poisson and negative binomial distributions of the densities of Diaphania spp. sampled by beating leaf of cucumber in the apical and basal thirds of the canopy (Tocantins, Minas Gerais, Brazil)

\begin{tabular}{|c|c|c|c|c|}
\hline \multirow[t]{2}{*}{ Plantation $^{a}$} & \multicolumn{2}{|c|}{$\begin{array}{l}\text { Tray in the } \\
\text { median third }\end{array}$} & \multicolumn{2}{|c|}{$\begin{array}{l}\text { Tray in the } \\
\text { basal third }\end{array}$} \\
\hline & $\chi^{2}$ & $\mathrm{df}$ & $\chi^{2}$ & $\mathrm{df}$ \\
\hline \multicolumn{5}{|l|}{ Poisson distribution } \\
\hline 1 & $12.43^{*}$ & 2 & $18.25^{*}$ & 2 \\
\hline 2 & $14.25^{*}$ & 2 & $21.44 *$ & 2 \\
\hline 3 & $1.85^{\mathrm{NS}}$ & 1 & $5.36^{\mathrm{NS}}$ & 2 \\
\hline 4 & $170.89^{*}$ & 7 & $157.51^{*}$ & 7 \\
\hline 5 & $27.41^{*}$ & 2 & $14.11 *$ & 1 \\
\hline 6 & $3.16^{\mathrm{NS}}$ & 1 & $3.86^{*}$ & 1 \\
\hline \multicolumn{5}{|c|}{ Negative binomial distribution } \\
\hline 1 & $5.54^{\mathrm{NS}}$ & 3 & $2.17^{\mathrm{NS}}$ & 4 \\
\hline 2 & $0.32^{\mathrm{NS}}$ & 3 & $2.47^{\mathrm{ns}}$ & 3 \\
\hline 3 & $10.44^{*}$ & 1 & $1.52^{\mathrm{NS}}$ & 1 \\
\hline 4 & $14.88^{\mathrm{NS}}$ & 14 & $13.64^{\mathrm{NS}}$ & 13 \\
\hline 5 & $5.43^{\mathrm{NS}}$ & 5 & $3.65^{\mathrm{NS}}$ & 4 \\
\hline 6 & $1.13^{\mathrm{NS}}$ & 1 & $0.07^{\mathrm{NS}}$ & 1 \\
\hline
\end{tabular}

* Significant at $5 \%$ probability; NS, nonsignificant at $5 \%$ probability.

${ }^{a}$ It was not possible to determine the statistical distributions of the data from plantations 7 tol0 because the number of degrees of freedom provided by analyzing these data was zero.

median and basal thirds and by WLC of the apical, median, and basal thirds occurred possibly because these techniques allow better visualization of the first, second, and third instars. The green color of the larvae contrasts with the white color of the tray. Better visualization of the green larvae in leaves was provided by the evaluation of leaves under artificial light in laboratory obtained by the technique of WLC than by direct counting of the larvae in the field.

The observation of greater densities of larvae of Diaphania spp. on leaves of the median and basal

Table 4. Chi-square test $\left(\chi^{2}\right)$ between observed and expected frequencies by Poisson and negative binomial distributions of the densities of hymenopteran parasitoids sampled by direct counting on leaf of cucumber in the apical and median thirds of the canopy (Tocantins, Minas Gerais, Brazil)

\begin{tabular}{|c|c|c|c|c|}
\hline \multirow[t]{2}{*}{ Plantation $^{a}$} & \multicolumn{2}{|c|}{$\begin{array}{c}\text { Direct counting } \\
\text { on the apical } \\
\text { third }\end{array}$} & \multicolumn{2}{|c|}{$\begin{array}{c}\text { Direct counting } \\
\text { in the median } \\
\text { third }\end{array}$} \\
\hline & $\chi^{2}$ & $\mathrm{df}$ & $\chi^{2}$ & $\mathrm{df}$ \\
\hline \multicolumn{5}{|l|}{ Poisson distribution } \\
\hline 1 & $7.62 *$ & 1 & $62.13^{*}$ & 2 \\
\hline 2 & $4.28^{*}$ & 1 & $1.33^{\mathrm{NS}}$ & 1 \\
\hline 3 & $26.46^{*}$ & 3 & $33.09 *$ & 3 \\
\hline 4 & $5.61^{*}$ & 1 & $5.99 *$ & 1 \\
\hline 6 & $0.85^{\mathrm{NS}}$ & 1 & $8.14^{*}$ & 2 \\
\hline 9 & $0.33^{\mathrm{NS}}$ & 1 & $4.51^{\mathrm{NS}}$ & 2 \\
\hline \multicolumn{5}{|c|}{ Negative binomial distribution } \\
\hline 1 & $3.14^{\mathrm{NS}}$ & 3 & $10.55^{\mathrm{NS}}$ & 6 \\
\hline 2 & $0.19^{\mathrm{NS}}$ & 1 & $2.51^{\mathrm{NS}}$ & 2 \\
\hline 3 & $1.65^{\mathrm{NS}}$ & 6 & $7.35^{\mathrm{NS}}$ & 7 \\
\hline 4 & $2.84^{\mathrm{NS}}$ & 1 & $1.68^{\mathrm{NS}}$ & 2 \\
\hline 6 & $0.14^{\mathrm{NS}}$ & 1 & $0.28^{\mathrm{NS}}$ & 2 \\
\hline 9 & $3.01^{\mathrm{NS}}$ & 2 & $3.80^{\mathrm{NS}}$ & 3 \\
\hline
\end{tabular}

* Significant at $5 \%$ probability; NS, nonsignificant at $5 \%$ probability.

${ }^{a}$ It was not possible to determine the statistical distributions of the data from plantations $5,7,8$, and 10 because the number of degrees of freedom provided by analyzing these data was zero. 

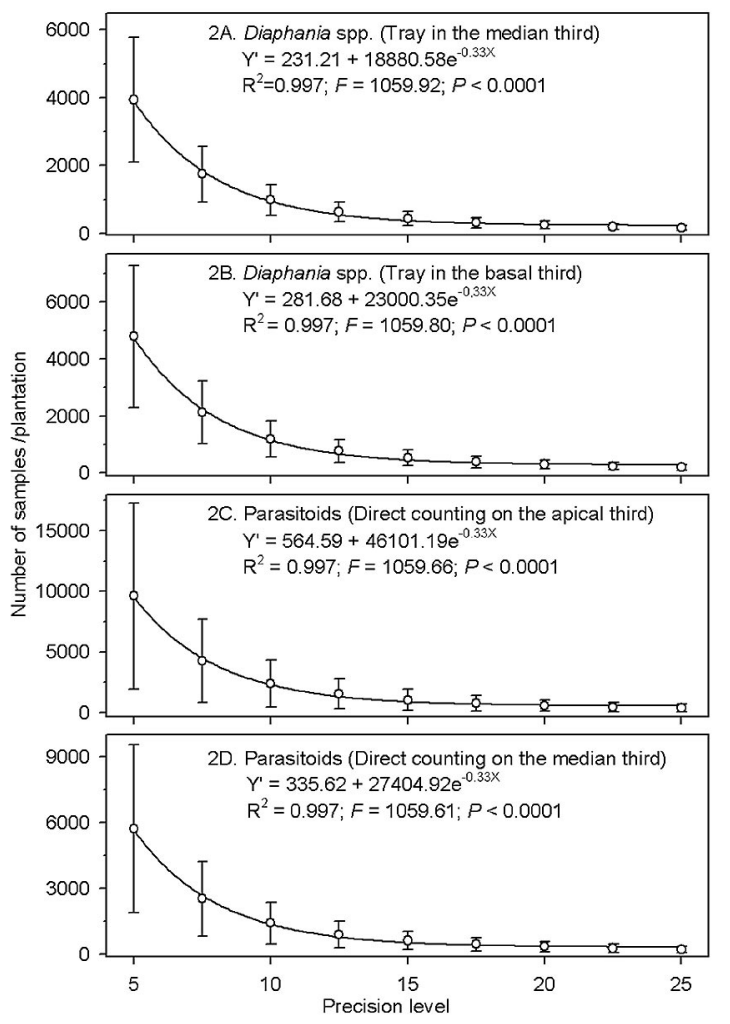

Fig. 2. Number of samples to compose the sampling system as function of the precision level of the sampling of Diaphania spp. by beating leaf of cucumber of the median $(2 \mathrm{~A})$ and basal (2B) third of the canopy and hymenopteran parasitoids by direct counting on leaf of the apical (2C) and median (2D) third of the canopy on leaves of cucumber plants. Tocantins, Minas Gerais, Brazil. Data are mean \pm SD.

thirds of the canopy was possibly because these leaves possess greater area, besides being older, and therefore they were exposed longer to the insects. Moreover, the median and basal leaves are closer to the fruit, facilitating the dispersal of the larvae (third instars) to the fruit (Sorensen and Baker 1983). Morphological and chemical characteristics such as higher density of nonglandular trichomes and glandular trichomes associated with leaves of the apical third of the canopy also may influence the lower level of attack. Nonglandular trichomes exert mechanical influ- ence on the oviposition, and glandular trichomes exert their effect through chemical substances (Antônio et al. 2002)

The greatest densities of hymenopteran parasitoids were observed when the technique of DC of the median third of the canopy was used, perhaps because of the high flight dispersion of the hymenopteran parasitoids caused by manipulation when beating a leaf on the tray or by collecting it. In addition, WLC caused the death of insects, which adhered to the plastic bag in condensed water caused by leaf transpiration. These insects were not counted.

The lower relative variances found in sampling Diaphania spp. by BLPT of the median and basal thirds of the canopy and by WLC of the three thirds of the canopy were because of the high densities of larvae in these samplings (relative variance is inversely proportional to the densities) (Pedigo 1988). The same relationship occurred with the hymenopteran parasitoids, which showed the lowest relative variances in the systems with greater densities.

The fastest samplings had lower costs because they used less labor, the main component of the sampling cost (97\%). BLPT and DC of insects needed less time than WLC for Diaphania spp. and hymenopteran parasitoid sampling because more operations (e.g., sacking, leaf collection, fastening of plastic bag, leaf removal from the plastic bag, and evaluation) were necessary in the leaf-collecting system than in the other systems. The sampling systems of BLPT and DC in the basal third of the canopy were more timeconsuming than in the other two thirds, because for sampling in the basal third, the sampler had to bend down to evaluate the plants.

The most suitable systems for sampling Diaphania spp. were BLPT of the median or basal third of the canopy, because these systems combined high precision, rapidity, and low cost. Although the systems that had used plastic bags had less relative variances, they had not been adjusted to the sampling of Diaphania spp., because they were slow and had high cost.

The more suitable systems for sampling hymenopteran parasitoids were the DC of the apical or median third of the canopy, because they combined high precision, rapidity, and low cost.

Determination of Number of Samples to Compose the Conventional Sampling Plan. The adjustment of the selected data of the systems for sampling Diapha-

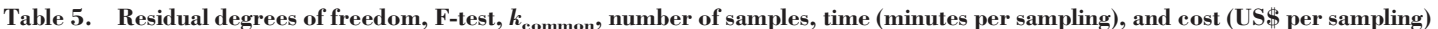
of the sampling system of Diaphania spp. and of hymenopteran parasitoids on cucumber crop (Tocantins, Minas Gerais, Brazil)

\begin{tabular}{|c|c|c|c|c|c|c|c|}
\hline \multirow{2}{*}{ Sampling system } & \multirow{2}{*}{$\begin{array}{c}\text { Residual } \\
\text { df }\end{array}$} & \multicolumn{2}{|c|}{$F$} & \multirow{2}{*}{$k_{\mathrm{common}}$} & \multirow{2}{*}{$\begin{array}{c}\text { No. } \\
\text { samples }\end{array}$} & \multirow{2}{*}{$\begin{array}{l}\text { Time } \\
(\min )\end{array}$} & \multirow{2}{*}{$\begin{array}{c}\text { Cost } \\
\text { (US\$) }\end{array}$} \\
\hline & & Inclination & Intercept & & & & \\
\hline \multicolumn{8}{|l|}{ Diaphania spp. } \\
\hline Tray in the median third & 6 & $9.22 *$ & $0.081^{\mathrm{NS}}$ & 1.5969 & 50 & 43.14 & 4.94 \\
\hline Tray in the basal third & 6 & $16.09 *$ & $0.082^{\mathrm{NS}}$ & 1.9670 & 44 & 39.41 & 4.51 \\
\hline \multicolumn{8}{|l|}{ Hymenopteran parasitoids } \\
\hline Direct counting on the apical third & 7 & $22.69 *$ & $0.020^{\mathrm{NS}}$ & 1.5890 & 77 & 66.46 & 17.03 \\
\hline Direct counting on the median third & 7 & $6.55^{*}$ & $0.001^{\mathrm{NS}}$ & 0.8335 & 74 & 65.29 & 16.73 \\
\hline
\end{tabular}

* Significant at $5 \%$ probability; NS, nonsignificant at $5 \%$ probability. 
nia spp. and hymenopteran parasitoids to the negative binomial distribution, in many of the plantations is because of the high frequency of samples with extreme densities (low or high). This results in obtaining variances greater than the average; the larger the quotient between variance and average, the higher are the values of parameter $k$ of the negative binomial distribution (Taylor 1984). This relationship also was observed in the present work. Negative binomial distributions were observed in the sampling of other lepidopterans, such as Spodoptera frugiperda (J.E. Smith) (Noctuidae) (Mitchell and Fuxa 1987), Pseudaletia unipuncta (Stoetzel) (Noctuidae) (Coggin and Dively 1982), and Leucoptera coffeella (Lyonetiidae) (Vilacorta and Tornero 1982).

Young and Young (1998) mentioned that different populations present distinct values of the parameter $k$ of the negative binomial distribution, thus resulting in different numbers of samples for each population. However, the selected systems for the economic precisions $k_{\text {common }}$ included variances that occurred in the populations of the different plantations. This makes possible the determination of a sampling strategy that is adjusted to many plantations. The objective was reached in this work; it was possible to find a $k_{\text {common }}$ for the more adequate sampling systems for Diaphania spp. and their hymenopteran parasitoids.

The sampling plans for Diaphania spp. and hymenopteran parasitoids can be considered useful according to the criteria described by Pedigo (1988), because these plans allow the collection, processing of the data (1.53 and $2.16 \mathrm{~min}$ ) and control decision making in $1 \mathrm{~d}$, besides being of low cost. Therefore, the adoption of such sampling plans in the culture of the cucumber might bring great benefits to the vegetable growers in reducing cost of control, preserving agroecosystems, and protecting human health.

\section{Acknowledgments}

This study was financed by the Conselho Nacional de Desenvolvimento Científico e Tecnológico and Fundação de Amparo à Pesquisa do Estado de Minas Gerais.

\section{References Cited}

Antônio, A. C., M. C. Picanço, A.H.R. Gonring, A. A. Semeão, L. M. Gontijo, and L. G. Sobrinho. 2002. Oviposição de Diaphania hyalinata L. (Lepidoptera: Pyralidae) afetada pela face foliar e tricomas. Acta Sci. 24: 359-362.

Bliss, C. L., and A.R.G. Owens. 1958. Negative binomial distributions with a common k. Biometrika 45: 37-58.

Coggin, D. L., and G. P. Dively. 1982. Sequential sampling plan for the armyworm in Maryland small grains. Environ. Entomol. 11: 169-172.

Dent, D. 2000. Insect pest management, 2nd ed. CAB Publishing, Wallingford, United Kingdom.

Doane, J. F., M. K. Mukerji, and O. Olfert. 2000. Sampling distribution and sequential sampling for subterranean stages of orange wheat blossom midge, Sitodiplosis mosellana (Géhin) (Diptera: Cecidomyidae) in spring wheat. Crop Prot. 19: 427-434.

Gonring, A.H.R., M. C. Picanço, R.N.C. Guedes, and E. M. Silva. 2003a. Natural biological control and key mortality factors of Diaphania hyalinata L. (Lepidoptera: Pyralidae) in cucumber. Biocontrol Sci. Technol. 13: 361366.

Gonring, A.H.R., M. C. Picanço, J. C. Zanuncio, and A. A. Semeão. 2003b. Natural biological control and key mortality factors of the pickleworm, Diaphania nitidalis Stoll (Lepidoptera: Pyralidae), in cucumber. Biol. Agric. Hortic. 20: 365-380.

Gusmão, M. R., M. C. Picanço, J. C. Zanuncio, D.J.H. Silva, and J.A.F. Barrigossi. 2005. Standardised sampling plan for Bemisia tabaci (Homoptera: Aleyrodidae) in outdoor tomatoes. Sci. Hortic. 103: 403-412.

Kogan, M., and D. C. Herzog. 1980. Sampling methods in soybean entomology. Springer, New York.

Ludwig, J. A., and J. F. Reynolds. 1988. Statistical ecology: a primer on methods and computing. Wiley, New York.

Miranda, M.M.M., M. Picanço, J. C. Zanuncio, and R.N.C. Guedes. 1998. Sampling and non-action levels for predators and parasitoids of virus vectors and leaf miners of tomato in Brazil. Med. Fac. Landbouww. Univ. Gent. 63: $519-523$.

Mitchell, F. L., and J. R. Fuxa. 1987. Distribution, abundance, and sampling of fall armyworm (Lepidoptera: Noctuidae) in south-central Louisiana corn fields. Environ. Entomol. 16: 453-458.

Moura, M. F., M. C. Picanço, E. M. Silva, R.N.C. Guedes, and J. L. Pereira. 2003. Plano de amostragem do biótipo B de Bemisia tabaci na cultura do pepino. Pesqu. Agropecu. Bras. 38: 1-7.

Navas, V.E.S., J. E. Funderburd, T. P. Mack, R. J. Beshear, and S. M. Olson. 1994. Aggregation indices and sample size curves for binomial sampling of flower-inhabiting Frankliniella species (Thysanoptera: Thripidae) on tomato. J. Econ. Entomol. 87: 1622-1626.

Pedigo, L.P. 1988. Entomology and pest management. Macmillan, New York.

Pedigo, L. P., G. D. Butin, and E. J. Bechinski. 1982. Flushing technique and sequential-count plan for green cloverworm (Lepidoptera: Noctuidae) months in soybeans. Environ. Entomol. 11: 1223-1228.

Pedigo, L. P., and M. R. Zeiss. 1996. Analyses in insect ecology and management. Iowa State University Press, Ames, IA.

Picanço, M. C., M. R. Gusmão, and T. L. Galvan. 2000. Manejo integrado de pragas de hortaliças, pp. 275-324. In L. Zambolim [ed.], Manejo integrado de doenças, pragas e ervas daninhas. Suprema, Viçosa, Minas Gerais, Brasil.

SAEG Software. 2001. SAEG Análises estatísticas no SAEG Guia do usuário, versão 8. UFV, Viçosa, Brazil.

Smith, H. A., J. L. Capineira, J. E. Peña, and B. LimboTerhaar. 1994. Parasitism of pickleworm and melonworm (Lepidoptera: Pyralidae) by Cardiochiles diaphaniae (Hymenoptera: Braconidae). Biol. Control 23: 1283-1293.

Sorensen, K. A., and J. R. Baker. 1983. Insect and related pests of vegetables, some important, common, and potential pest in the southeastern United States, Report AG-295. The North Carolina Agricultural Extension Service, University of North Carolina, Raleigh, NC.

Southwood, T.R.E. 1978. Ecological methods, with particular reference to the study of insect populations, 2 nd ed. Chapman \& Hall, London, United Kingdom.

Sterling, W. L., E. Bleicher, and F.M.M. Jesus. 1983. Um programa de manejo integrado para Insects do algodoeiro no nordeste do Brasil usando amostragem seqüencial. An. Soc. Entomol. Bras. 12: 85-98.

Taylor, L. R. 1961. Aggregation, variance and the mean. Nature (Lond.) 189: 732-735. 
Taylor, L. R. 1984. Assessing and interpreting the spatial distribution of insects populations. Annu. Rev. Entomol. 29: 231-257.

Valles, S. M., J. L. Capinera, and P.E.A. Teal. 1991. Evaluation of pheromone trap design, height, and efficiency for capture of male Diaphania nitidalis. (Lepidoptera: Pyralidae) in a field cage. Environ. Entomol. 20: 12741278.
Vilacorta, A., and M.T.T. Tornero. 1982. Plano de amostragem seqüencial de dano causado por Perileucoptera coffeella no Paraná. Pesqu. Agropecu. Bras. 17: 1249-1260.

Young, L. J., and J. H. Young. 1998. Statistical ecology: a population perspective. Kluwer Academic Publishers, Boston, MA.

Received 30 May 2006; accepted 20 July 2006. 